\title{
Topical Application of Sadat-Habdan Mesenchymal Stimulating Peptide (SHMSP) Accelerates Wound Healing in Diabetic Rabbits
}

\author{
Abdulmohsen H. Al-Elq, ${ }^{1}$ Mir Sadat-Ali, ${ }^{2}$ Mohamed Elsharawy, ${ }^{3}$ Ibrahim Al-Habdan, ${ }^{4}$ \\ Fatin Othman Al-Aqeel, ${ }^{3}$ and Magda M. Naim ${ }^{5}$ \\ ${ }^{1}$ Department of Internal Medicine, University of Dammam, Dammam, Saudi Arabia \\ ${ }^{2}$ King Fahd Hospital of the University, P.O. Box 40071, Al-Khobar 31952, Saudi Arabia \\ ${ }^{3}$ Department of General Surgery, University of Dammam, Dammam, Saudi Arabia \\ ${ }^{4}$ Department of Orthopaedic Surgery, University of Dammam, Dammam, Saudi Arabia \\ ${ }^{5}$ Department of Histology, Suez Canal University, Ismalia, Egypt
}

Correspondence should be addressed to Mir Sadat-Ali,drsadat@hotmail.com

Received 20 March 2012; Revised 28 April 2012; Accepted 7 May 2012

Academic Editor: A. Veves

Copyright (C) 2012 Abdulmohsen H. Al-Elq et al. This is an open access article distributed under the Creative Commons Attribution License, which permits unrestricted use, distribution, and reproduction in any medium, provided the original work is properly cited.

\begin{abstract}
Objective. Diminished wound healing is a common problem in diabetic patients due to diminished angiogenesis. SHMSP was found to promote angiogenesis. The present study was carried out to examine the effect of this peptide in healing of wounds in diabetic rabbits. Materials and Methods. Twenty male New Zealand rabbits were used in this study. Diabetes mellitus was induced and the rabbits were randomly divided into two equal groups: control group and peptide group. A-full thickness punch biopsy was made to create a wound of about $10 \mathrm{~mm}$ on the right ears of all rabbits. Every day, the wound was cleaned with saline in control groups. In the peptide group, $15 \mathrm{mg}$ of SHMSP was applied after cleaning. On day 15th, all animals were sacrificed, and the wounds were excised with a rim of $5 \mathrm{~mm}$ of normal surrounding tissue. Histo-pathological assessment of wound healing, inflammatory cell infiltration, blood vessel proliferation, and collagen deposition was performed. Results. There were no deaths among the groups. There was significant increase in wound healing, blood vessel proliferation and collagen deposition, and significant decrease in inflammatory cell infiltration in the peptide group compared to the control group. Conclusion. Topical application of SHMSP improves wound healing in diabetic rabbits.
\end{abstract}

\section{Introduction}

Impaired wound healing is a common complication of diabetes. Diminished production of growth factors and decreased angiogenesis are thought to contribute to impaired healing of chronic wounds [1]. Angiogenesis is necessary to allow migration of leukocytes and growth factors and oxygen supply during granulation tissue formation. Growth factors and particularly the Vascular Endothelial Growth Factor (VEGF) play an important role in the induction of angiogenesis [2]. Reductions of several growth factors were found to occur in diabetic animals [3]. Application of such growth factors was shown to facilitate wound closure in animals and humans [4-6]. The first approved topically applied growth factor is the recombinant human
Platelets Derived Growth Factor (hPDGF-BB). In previous studies, topical application of the hPDGF-BB to acute and chronic wounds resulted in faster complete wound closure than the control wounds $[7,8]$. Several other growth factors have been recently used for therapeutic angiogenesis [2].

SHMSP is 13 amino acids peptide, having a molecular weight of 1465 daltons and synthesized in the laboratory. It is absorbed in the body and excreted from the kidney [9]. It was shown to stimulate bone growth and accelerate the healing of bone fracture by way of angiogenesis [10]. On the other hand the rabbit ear ulcer model was found to be favorable animal wound-healing model because it leads to full-thickness noncontractile excisional wound with avascular base [11]. This study was carried out with an 

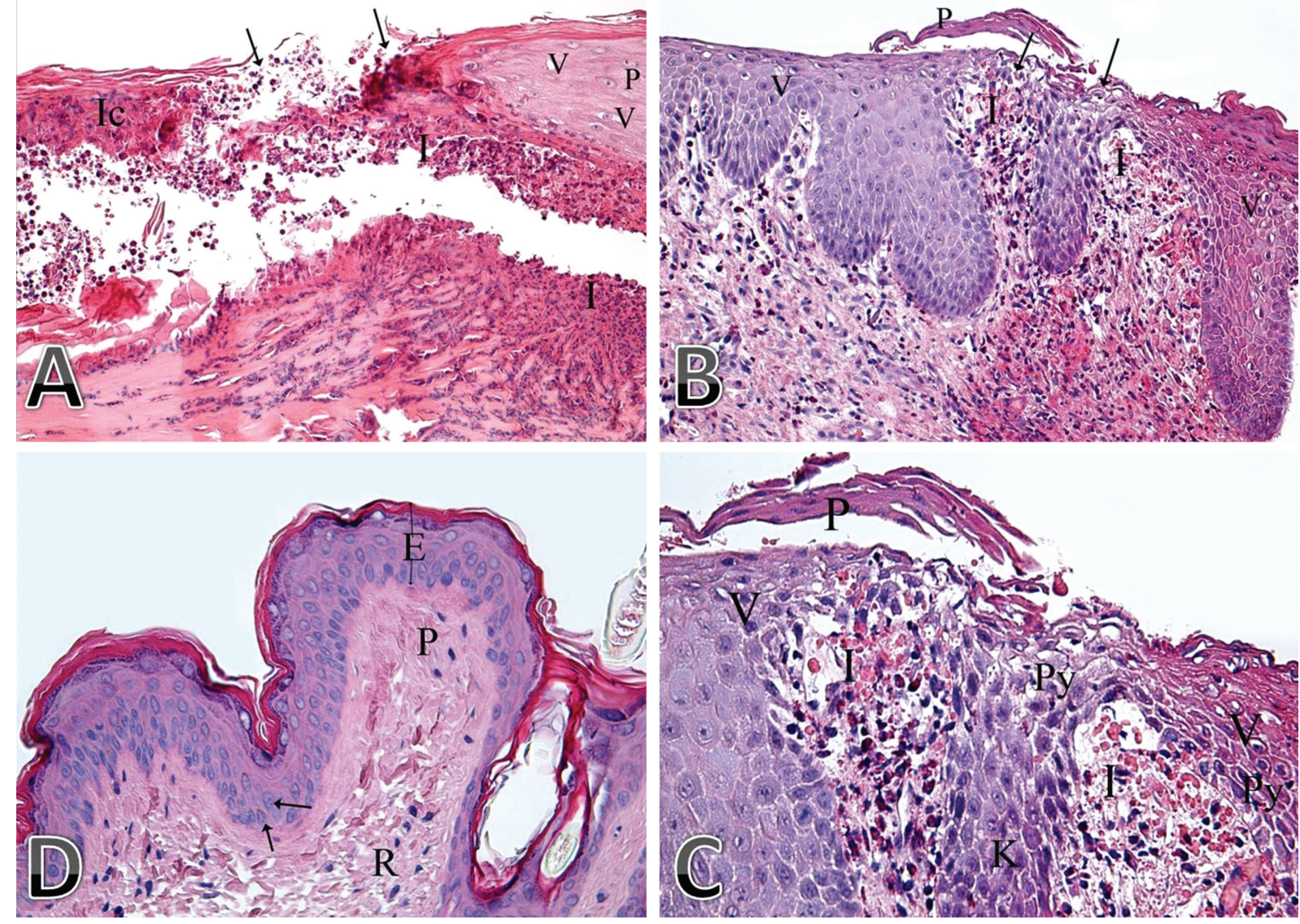

Figure 1: (A, B, and C) Photomicrograph of a skin section from control group showing (A) nonhealed ulcer (arrows). There is dermoepidermal separation due to presence of marked inflammatory cell infiltration (I). The epidermal cells on the left side of the photo are replaced by inflammatory cells (Ic), and those on the right side of the photo show cytoplasmic vacuolation (V) and pyknosis (P) of some of their nuclei. (H\&E $\times 200)$. (B) Incomplete healing of the ulcer (arrow) due to presence of marked inflammatory cell infiltration (I). The epidermal cells on both sides of the ulcer area show marked increase in thickness (acanthosis), and lots of them appeared vacuolated $(\mathrm{V})$. Note also the presence of parakeratosis (P; presence of nuclei in keratin layer), $(\mathrm{H} \& \mathrm{E} \times 200)$. (C) High-power view of the previous photo. There is marked increase in epidermal thickness on both sides of the ulcer area, marked cellular infiltration (I), parakeratosis (P), and vacuolated epidermal cells (V). Some of the epidermal cells also show pyknosis (Py) or karyolysis (K) of their nuclei (H\&E $\times 400)$. (D) Photomicrograph of a skin section from the peptide group showing complete healing of the ulcer and normal appearance of both the epidermis (E) and dermis (papillary dermis; P and reticular dermis; R). Note also that some of the epidermal cells show mitotic figures (arrow) $(\mathrm{H} \& \mathrm{E} \times 400)$.

objective to evaluate the efficacy of SHMSP in the wound healing of alloxan-induced diabetic rabbits and to study its angiogenesis effect on wounds of such animals.

\section{Materials and Methods}

The experimental study was performed in accordance with the national laws for the principles of laboratory care on animal experiments. It was carried out at the Departments of Medicine, Orthopedic and Surgery, University of Dammam, Saudi Arabia and Histology Department, Faculty of Medicine, Suez Canal University, Egypt in the period between July 2010 and September 2010. Ethical approval had been obtained from the local committee at King Faisal University.
Twenty apparently healthy New Zealand male rabbits, $\geq 12$ weeks old and weighing between 3 and $5 \mathrm{~kg}$, were used in this study. Animals were kept in large cages with free mobility and fed with standard rabbit diet. They were provided with food and water ad libitum and maintained at $25-28^{\circ} \mathrm{C}$. Cages were changed routinely every day. Diabetes mellitus was induced by a single intraperitoneal injection of freshly prepared alloxan (Sigma Chemical, USA) at a dose of $160 \mathrm{mg} / \mathrm{kg}$ of body weight to overnight fasting animal in total volume of $0.5 \mathrm{~mL}$ [12]. After treatment, water containing $1 \%$ dextrose was given to rabbits for 48 hours to avoid hypoglycemia. The blood sugar was then measured daily using blood glucose tests strips and meter (ACCU-CHECK, Roche Diagnostics). No rabbit experienced hypoglycemia $(<70 \mathrm{mg} / \mathrm{dL})$ or marked hyperglycemia $(>600 \mathrm{mg} / \mathrm{dL})$. After one week of having blood sugar of more than $250 \mathrm{mg} / \mathrm{dL}$, 

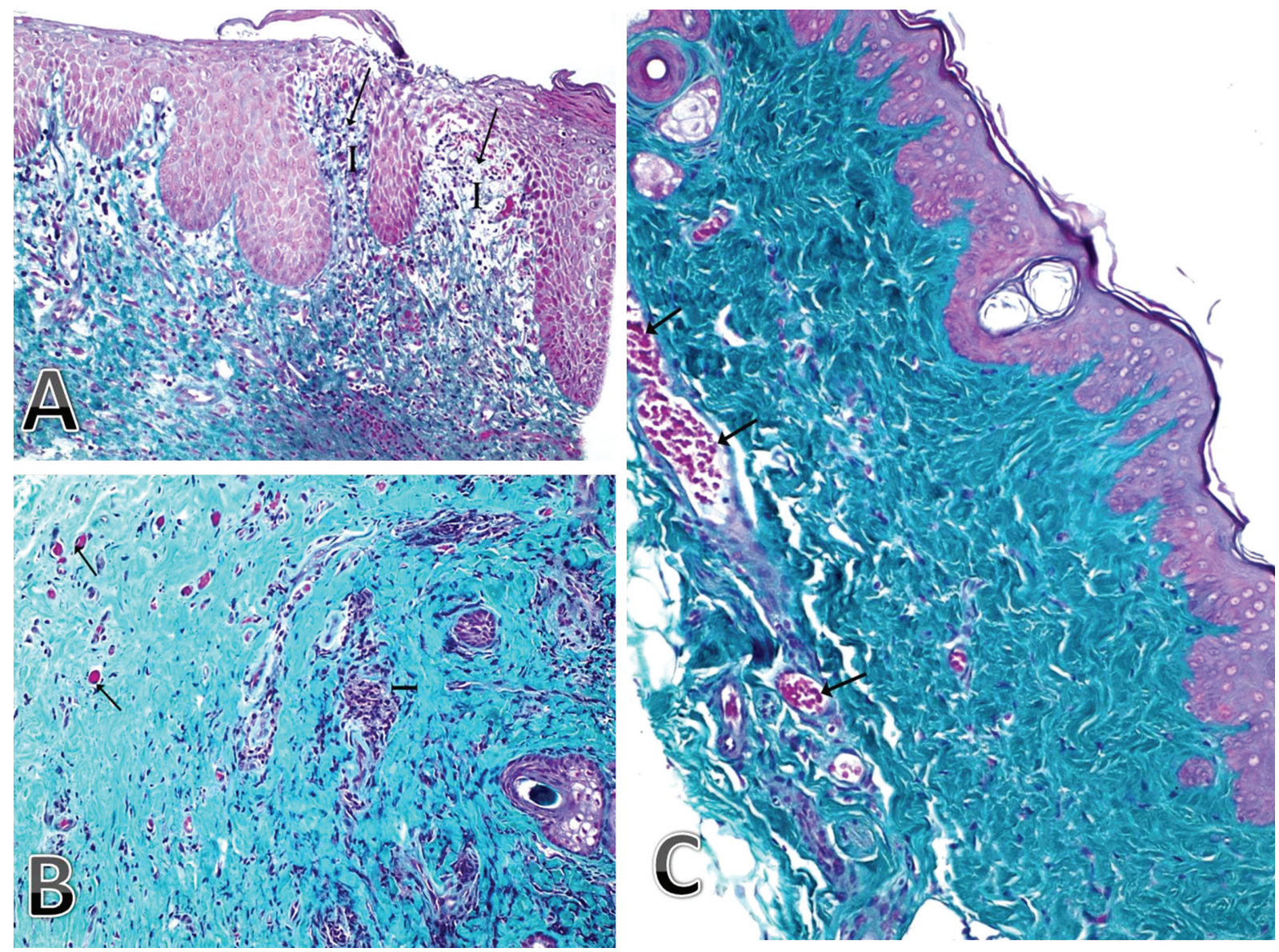

Figure 2: (A and B) Photomicrograph of a skin section from control group showing (A) few collagen fibers under the ulcer (arrow) where the area is replaced by marked inflammatory cell infiltration (I) (Masson's trichrome $\times 200$ ). (B) An area of the dermis with small and few vasculature (small blood vessels; arrow); however, inflammatory cell infiltration (I) is shown (Masson's trichrome $\times 200$ ). (C) Photomicrograph of a skin section from the peptide-treated group showing normal appearance of collagen fibers and presence of good vasculature in the dermis (many large blood vessels; arrow) (Masson's trichrome $\times 200$ ).

rabbits were randomly divided into two equal groups, control group, and peptide treated group (10 rabbits each). A sterile $10-\mathrm{mm}$ diameter punch biopsy was used to create single full-thickness wound on the right ear of each rabbit under anesthesia. Every day, the wound was cleaned with normal saline in the control group while, in the diabetic group, $15 \mathrm{mg}$ of the SHMSP was applied once daily after cleaning to cover the whole wound area. No dressings were applied at the site of the wound throughout the duration of the experiment. On day 15th, all animals were sacrificed, and the wounds' sites were excised with a rim of $5 \mathrm{~mm}$ of normal surrounding skin. Tissue specimens were fixed in $10 \%$ neutral buffered formalin solution. They were then processed to prepare $5 \mathrm{~mm}$-thick paraffin sections for histological stains (H\&E, Masson trichrome and reticulin stains) [13]. Skin sections were assessed by light microscopy for wound healing, inflammatory cell infiltration, blood vessel proliferation, and collagen deposition. Wound healing was assessed in H\&E sections. Reticulin stain aimed at detecting early events of wound healing.
Quantitative analyses of digital images were made with Super eye-Heidi software (Heidi Software Company, Cairo, Egypt). Images were obtained with a CCD video Camera (HS-CC721) mounted on a Microscope (Olympus BH-2). Measurement of the following was performed: (1) area percentage of inflammatory cells in H\&E-stained sections, (2) color area percentage of collagen fibers in Masson's trichrome stained sections, (3) vascular area density: percentage of blood vessel area per wound area, and (4) vessel Index $\left(\right.$ vessels $/ \mathrm{mm}^{2}$ ) [14]. Both vascular area density and Vessel Index were measured in Masson's trichrome stained. The image analyzer was calibrated for color and distance measurements before use.

Statistical Analysis. Chi square test or Fisher's exact test, was used as appropriate to assess differences in wound healing between groups. Other results were summarized using descriptive statistics. These were presented as mean \pm SD and compared using Student $t$-test. Significance was set at 


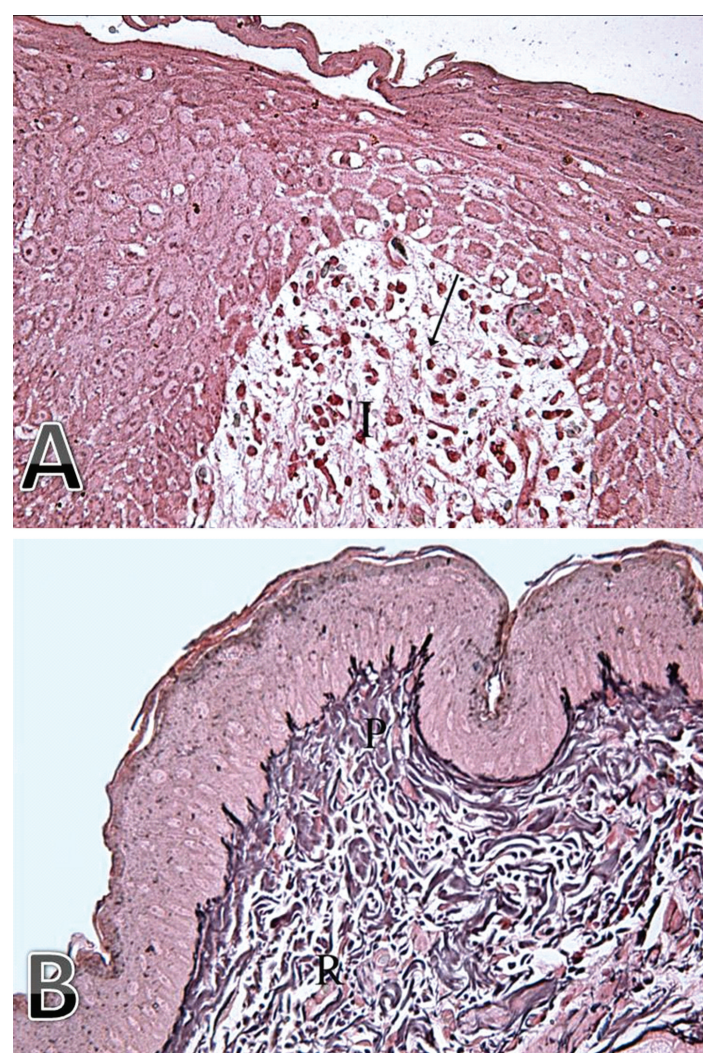

FIgURE 3: (A) Photomicrograph of a skin section from control group showing loss of reticulin fibers under the ulcer (arrow) where the area is replaced by marked inflammatory cell infiltration (I) (Reticulin stain $\times 400$ ). (B) Photomicrograph of a skin section from peptide-treated group showing normal appearance of reticular fibers (black colored) in both the papillary $(\mathrm{P})$ and reticular $(\mathrm{R})$ dermis (Reticulin stain $\times 400$ ).

$P<0.05$ for all comparisons. All statistical analyses were performed with the aid of SPSS 15 (SPSS Inc, Chicago, IL, USA) software.

\section{Results}

All alloxan-treated rabbits developed hyperglycemia within 72 hours. There were no deaths among the groups. Most of the control group showed evidence of nonhealed ulcer and marked inflammatory cell infiltration. The epidermal cells on both sides of the ulcer area showed acanthosis (marked increase in thickness) with cytoplasmic vacuolation, pyknosis, and karyolysis of their nuclei. Parakeratosis (presence of nuclei in keratin layer) was also evident in some cases. Reticulin stain revealed few reticular fibers under the wound. There was also small number of collagen fibers under the ulcer with scattered short blood vessels (Figure 1). On the other hand, the peptide group revealed complete healing of most of the ulcers and normal appearance of both the epidermis and dermis, normal appearance of collagen fibers in both the epidermis and dermis with normal vasculature (Figure 2). Using Reticulin stain, the reticular fibers appeared normal in the peptide-treated group (Figure 3 ). The growth
TABLE 1: Histological analysis of control and peptide treated groups.

\begin{tabular}{lccc}
\hline & Control & Peptide treated & $P$ value \\
\hline Healing & $2 / 10$ & $7 / 10$ & 0.025 \\
Vascular area density $(\%)$ & $9.37 \pm 5.81$ & $21.15 \pm 4.04$ & 0.036 \\
Vessel Index (vessels $\left./ \mathrm{mm}^{2}\right)$ & $26.7 \pm 7.44$ & $50.13 \pm 10.71$ & $<0.0001$ \\
$\begin{array}{l}\text { Color area percentage of } \\
\text { collagen fibers }\end{array}$ & $35.45 \pm 5.82$ & $43.09 \pm 6.42$ & 0.013 \\
$\begin{array}{l}\text { Area percentage of } \\
\text { Inflammatory cell }\end{array}$ & $35.08 \pm 15.07$ & $10.02 \pm 1.31$ & $<0.0001$ \\
\hline
\end{tabular}

of new blood vessels was also assessed using CD31 tissue marker stain which revealed widespread and longer vascular channels in the peptide-treated group as compared to the control group (Figure 4).

Quantitative analyses of digital images revealed highly significance lower percentage of inflammatory cells in the treated group as compared to the control $(P$ value $<0.0001)$. Collagen deposition as a marker of wound healing was also significantly higher in the treated group. There was clear evidence of enhancement of angiogenesis by SHMSP with significantly higher vessel index $(50.13 \pm 10.71$ versus $26.7 \pm$ 7.44, $P$ value $<0.0001)$ and vascular area density in the peptide-treated group as compared to the control group (Table 1).

\section{Discussion}

Diabetes mellitus is increasing in incidence and represents a major health problem for the 21st century. The total number of diabetic patients is expected to increase from 171 million individuals in 2000 to 439 million individuals in 2030 compromising around $7.7 \%$ of the world population [15]. One of the main complications of diabetes is foot ulcer affecting from $1.0 \%$ to $4.1 \%$ of patients while the annual incidence of amputation is $0.21-1.37 \%$ [16]. The process of wound healing has three important components: inflammation, proliferation, and tissue remodeling. Inflammatory phase requires functioning immune system. The proliferative phase requires deposition of collagen, and angiogenesis or new vessels formation. During the remodeling phase, reorganization of collagen occurs that leads to restoration of tissue structural integrity [17-19]. In diabetes mellitus these three phases are affected. There is depression of immune system causing increase incidence of wound infection with suppression of angiogenesis and collagen formation [20]. The present study assessed the effect of SHSMP on the above processes during healing of diabetic wounds.

Within 72 hours, blood sugar measurement indicated the presence of hyperglycemia which persisted during the period of this study. Diabetes mellitus was found in many experimental and clinical studies to increase markers of wound infection manifested by increased inflammatory cells [21-23]. Wound infection is one of the most common causes of delayed wound healing [24], while prevention and treatment of wound infection promotes the healing process [25]. This study revealed that topical application of SHMSP 


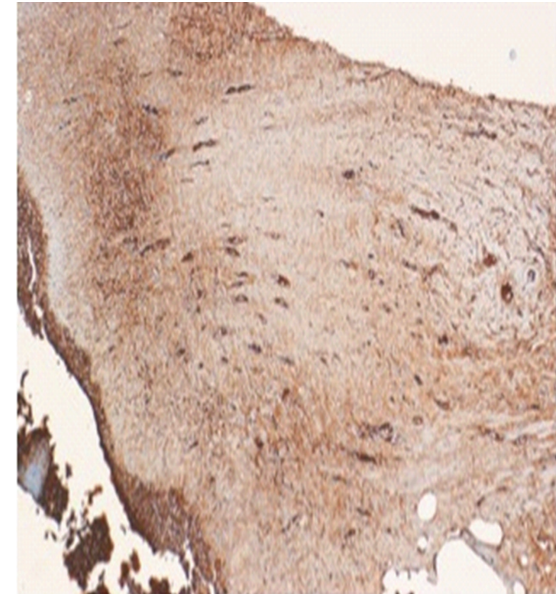

(a)

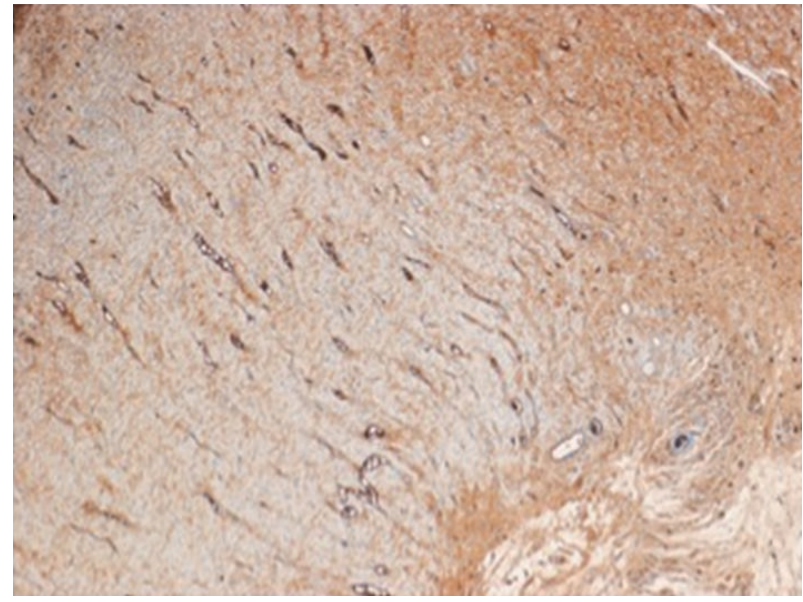

(b)

FIgURE 4: (a) Photomicrograph of a skin section from control group showing few short vascular channels. (b) Photomicrograph of a skin section from peptide-treated group showing widespread long vascular channels (CD31 tissue marker stain, $\times 100)$.

on diabetic wound significantly decreases inflammatory cells and thereby improves healing. It is well established that one of the essential components of normal wound healing is the formation of new blood vessels within the wound matrix referred to as granulation tissue $[20,26]$. Diabetes mellitus has been shown to be associated with decrease in number and function of circulating endothelial progenitor cells $[27,28]$, hence, impaired angiogenesis and wound healing $[29,30]$. Our study revealed significant enhancement of angiogenesis in the SHMSP-treated group as compared to the control group. SHMSP was also found earlier to enhance angiogenesis in normoglycemic animals [9]. This study further proved that it could also increase angiogenesis in wounds created in diabetic animals. Any factor which improves angiogenesis in the wound should improve wound healing. Delay in healing of diabetic wound was also reported to be due to impaired fibroblast migration [31]. This will result in reduction of collagen deposition and impediment in wound healing. Reticular fibers are formed mainly of collagen type III which constitutes about $15 \%$ of dermal collagen, in association with other types of collagen, glycoprotein (fibronectin), and proteoglycan [32]. It was also reported that fibronectin and collagen type III (reticular fibers) are major constituents of early wound architecture [33]. We think that part of improved wound healing of diabetic rabbits by SHMSP in this study is due to enhancement of collagen deposition and increased reticular fiber formation.

One of mechanisms of VEGF in accelerating experimental diabetic wound healing is stimulating the migration of cultured human keratinocytes and fibroblasts, thus revealing a nonangiogenic effect of VEGF on wound closure [34]. Apparently the same mechanism would apply also for SHMSP which was found in this study to improve collagen deposition, in addition to angiogenesis, and hence promoted diabetic wound healing. Other possible mechanism of improved wound healing by SHMSP in the present study is that this peptide possibly acted like a bone morphogenetic protein (BMP) through stimulation of the basic cellular model at the injury site. It was shown previously that when SHMSP was used in a fracture model, it stimulated osteoblasts formation with deposition of new bone in the early stage of fracture healing [10]. Bone morphogenetic proteins (BMPs) are known to be osteoinductive and stimulated bone formation. Recent reports indicated that BMPs may play a role in angiogenesis as well. Finkenzeller et al. (2012) [35] conclusively showed that BMP-2 stimulates vasculogenesis and angiogenesis. Limitations of this study are the lack of assessment of wound closure and wound volume through imaging and wound tracing and the lack of comparison with finding from baseline skin biopsies. Additional studies should look at the systemic effect of SHMSP and the effect of longer period of hyperglycemia.

\section{In Conclusion}

Topical application of SHMSP on diabetic wound decreases inflammatory cell infiltration and stimulates blood vessel proliferation and collagen deposition. This can reduce incidence of infection and accelerate wound healing in diabetic rabbits.

\section{References}

[1] S. M. Bauer, R. J. Bauer, and O. C. Velazquez, "Angiogenesis, vasculogenesis, and induction of healing in chronic wounds," Vascular and Endovascular Surgery, vol. 39, no. 4, pp. 293-306, 2005.

[2] W. W. Li, K. E. Talcott, A. W. Zhai, E. A. Kruger, and V. W. $\mathrm{Li}$, "The role of therapeutic angiogenesis in tissue repair and regeneration," Advances in Skin \& Wound Care, vol. 18, no. 9, pp. 491-502, 2005. 
[3] O. Ochoa, F. M. Torres, and P. K. Shireman, "Chemokines and diabetic wound healing," Vascular, vol. 15, no. 6, pp. 350-355, 2007.

[4] D. L. Brown, C. D. Kane, S. D. Chernausek, and D. G. Greenhalgh, "Differential expression and localization of insulin-like growth factors I and II in cutaneous wounds of diabetic and nondiabetic mice," American Journal of Pathology, vol. 151, no. 3, pp. 715-724, 1997.

[5] M. Kalani, J. Apelqvist, M. Blombäck et al., "Effect of dalteparin on healing of chronic foot ulcers in diabetic patients with peripheral arterial occlusive disease: a prospective, randomized, double-blind, placebo-controlled study," Diabetes Care, vol. 26, no. 9, pp. 2575-2580, 2003.

[6] V. K. Mohan, "Recombinant human epidermal growth factor (REGEN-D 150): effect on healing of diabetic foot ulcers," Diabetes Research and Clinical Practice, vol. 78, no. 3, pp. 405411, 2007.

[7] M. A. Cohen and W. H. Eaglstein, "Recombinant human platelet-derived growth factor gel speeds healing of acute fullthickness punch biopsy wounds," Journal of the American Academy of Dermatology, vol. 45, no. 6, pp. 857-862, 2001.

[8] J. M. Smiell, T. J. Wieman, D. L. Steed, B. H. Perry, A. R. Sampson, and B. H. Schwab, "Efficacy and safety of becaplermin (recombinant human platelet-derived growth factor-BB) in patients with nonhealing, lower extremity diabetic ulcers: a combined analysis of four randomized studies," Wound Repair and Regeneration, vol. 7, no. 5, pp. 335-346, 1999.

[9] M. Sadat-Ali, I. Al-Habdan, and M. A. Shawarby, "Angiogenesis: a new factor on the block-a preliminary observation," International Journal of Angiology, vol. 14, no. 2, pp. 87-91, 2005.

[10] M. Sadat-Ali, M. Sadat-Ali, and I. Al-Habdan, "Osteogenic activity of Sadat-Habdan mesenchymal stimulating peptide in diaphyseal segmental defects," Saudi Medical Journal, vol. 29, no. 3, pp. 464-466, 2008.

[11] A. Breen, G. Mc Redmond, P. Dockery, T. O’Brien, and A. Pandit, "Assessment of wound healing in the alloxan-induced diabetic rabbit ear model," Journal of Investigative Surgery, vol. 21, no. 5, pp. 261-269, 2008.

[12] A. D. Chougale, S. N. Panaskar, P. M. Gurao, and A. U. Arvindekar, "Optimization of alloxan dose is essential to induce stable diabetes for prolonged period," Asian Journal of Biochemistry, vol. 2, pp. 402-408, 2007.

[13] J. D. Bancroft, H. C. Cook, and R. W. Stirling, "Connective tissues," in Manual of Histological Techniques and Their Diagnostic Application, chapter 3, pp. 48-50, Churchill Livingstone, 1994.

[14] E. Sivan-Loukianova, O. A. Awad, V. Stepanovic, J. Bickenbach, and G. C. Schatteman, "CD34+ blood cells accelerate vascularization and healing of diabetic mouse skin wounds," Journal of Vascular Research, vol. 40, no. 4, pp. 368-377, 2003.

[15] Y. M. K. Farag and M. R. Gaballa, "Diabesity: an overview of a rising epidemic," Nephrology Dialysis Transplantation, vol. 26, no. 1, pp. 28-35, 2011.

[16] C. L. Bartus and D. J. Margolis, "Reducing the incidence of foot ulceration and amputation in diabetes," Current Diabetes Reports, vol. 4, no. 6, pp. 413-418, 2004.

[17] J. Li, J. Chen, and R. Kirsner, "Pathophysiology of acute wound healing," Clinics in Dermatology, vol. 25, no. 1, pp. 9-18, 2007.

[18] C. L. Baum and C. J. Arpey, "Normal cutaneous wound healing: clinical correlation with cellular and molecular events," Dermatologic Surgery, vol. 31, no. 6, pp. 674-686, 2005.
[19] A. J. Singer and R. A. F. Clark, "Cutaneous wound healing," The New England Journal of Medicine, vol. 341, no. 10, pp. 738746, 1999.

[20] Z. J. Liu and O. C. Velazquez, "Hyperoxia, endothelial progenitor cell mobilization, and diabetic wound healing," Antioxidants and Redox Signaling, vol. 10, no. 11, pp. 18691882, 2008.

[21] A. Breen, G. Mc Redmond, P. Dockery, T. O’Brien, and A. Pandit, "Assessment of wound healing in the alloxan-induced diabetic rabbit ear model," Journal of Investigative Surgery, vol. 21, no. 5, pp. 261-269, 2008.

[22] T. Hachenberg, M. Sentürk, O. Jannasch, and H. Lippert, "Postoperative wound infections: pathophysiology, risk factors and preventive concepts," Anaesthesist, vol. 59, no. 9, pp. 851-868, 2010.

[23] A. Ata, J. Lee, S. L. Bestle, J. Desemone, and S. C. Stain, "Postoperative hyperglycemia and surgical site infection in general surgery patients," Archives of Surgery, vol. 145, no. 9, pp. 858-864, 2010.

[24] R. Edwards and K. G. Harding, "Bacteria and wound healing," Current Opinion in Infectious Diseases, vol. 17, no. 2, pp. 91-96, 2004.

[25] S. O'Meara, N. Cullum, M. Majid, and T. Sheldon, "Systematic reviews of wound care management: (3) antimicrobial agents for chronic wounds; (4) diabetic foot ulceration," Health Technology Assessment, vol. 4, no. 21, pp. 1-237, 2000.

[26] Y. Duraisamy, M. Slevin, N. Smith et al., "Effect of glycation on basic fibroblast growth factor induced angiogenesis and activation of associated signal transduction pathways in vascular endothelial cells: possible relevance to wound healing in diabetes," Angiogenesis, vol. 4, no. 4, pp. 277-288, 2001.

[27] G. P. Fadini, C. Agostini, and A. Avogaro, "Endothelial progenitor cells and vascular biology in diabetes mellitus: current knowledge and future perspectives," Current Diabetes Reviews, vol. 1, no. 1, pp. 41-58, 2005.

[28] C. J. M. Loomans, E. J. P. De Koning, F. J. T. Staal, T. J. Rabelink, and A. J. Van Zonneveld, "Endothelial progenitor cell dysfunction in type 1 diabetes: another consequence of oxidative stress?" Antioxidants and Redox Signaling, vol. 7, no. 11-12, pp. 1468-1475, 2005.

[29] A. Martin, M. R. Komada, and D. C. Sane, "Abnormal angiogenesis in diabetes mellitus," Medicinal Research Reviews, vol. 23, no. 2, pp. 117-145, 2003.

[30] H. Brem, T. Jacobs, L. Vileikyte et al., "Wound-healing protocols for diabetic foot and pressure ulcers," Surgical Technology International, vol. 11, pp. 85-92, 2003.

[31] H. Brem, O. Stojadinovic, R. F. Diegelmann et al., "Molecular markers in patients with chronic wounds to guide surgical debridement," Molecular Medicine, vol. 13, no. 1-2, pp. 30-39, 2007.

[32] L. C. Junqueira and J. Carniero, "Connective tissue," in Basic Histology, chapter 5, pp. 108-109, McGraw-Hill, 2005.

[33] L. A. Repesh, T. J. Fitzgerald, and L. T. Furcht, "Fibronectin involvement in granulation tissue and wound healing in rabbits," Journal of Histochemistry and Cytochemistry, vol. 30, no. 4, pp. 351-358, 1982.

[34] H. Brem, A. Kodra, M. S. Golinko et al., "Mechanism of sustained release of vascular endothelial growth factor in accelerating experimental diabetic healing," Journal of Investigative Dermatology, vol. 129, no. 9, pp. 2275-2287, 2009.

[35] G. Finkenzeller, S. Hager, and G. B. Stark, "Effects of bone morphogenetic protein 2 on human umbilical vein endothelial cells," Microvascular Research, vol. 84, no. 1, pp. 81-85, 2012. 


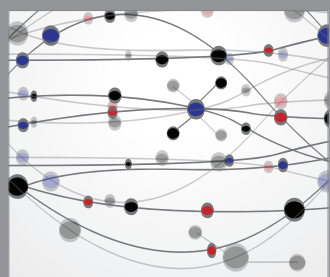

The Scientific World Journal
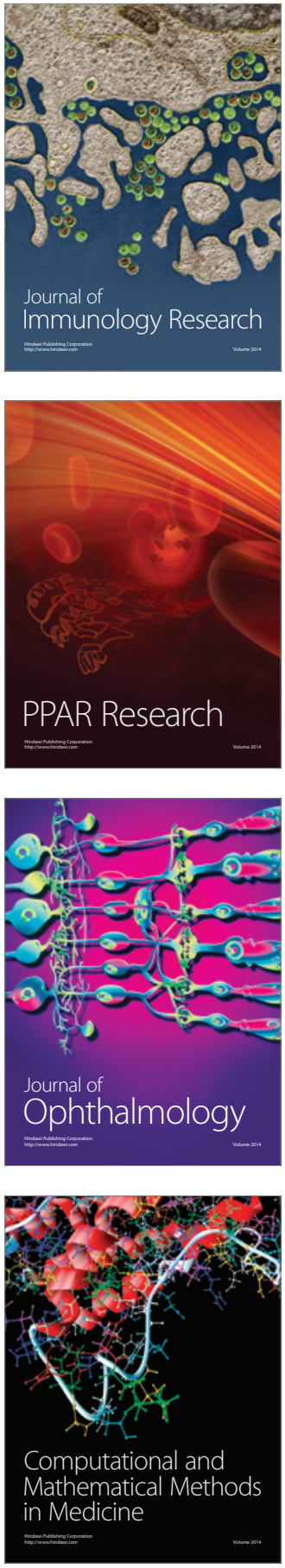

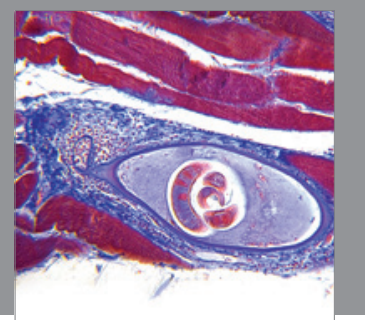

Gastroenterology

Research and Practice
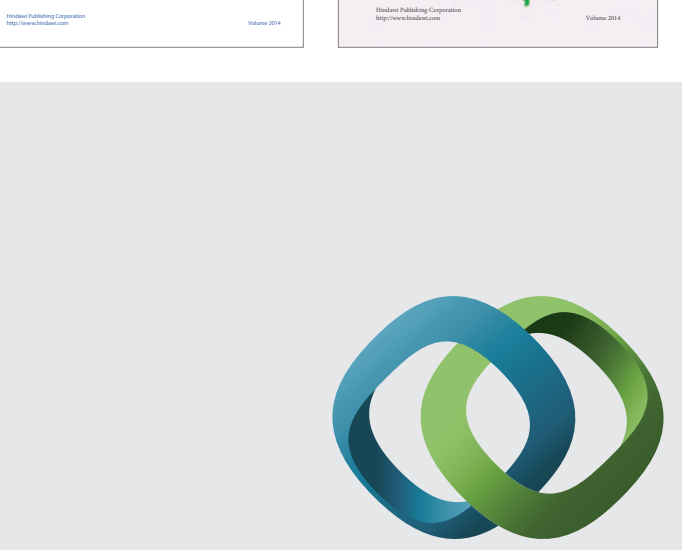

\section{Hindawi}

Submit your manuscripts at

http://www.hindawi.com
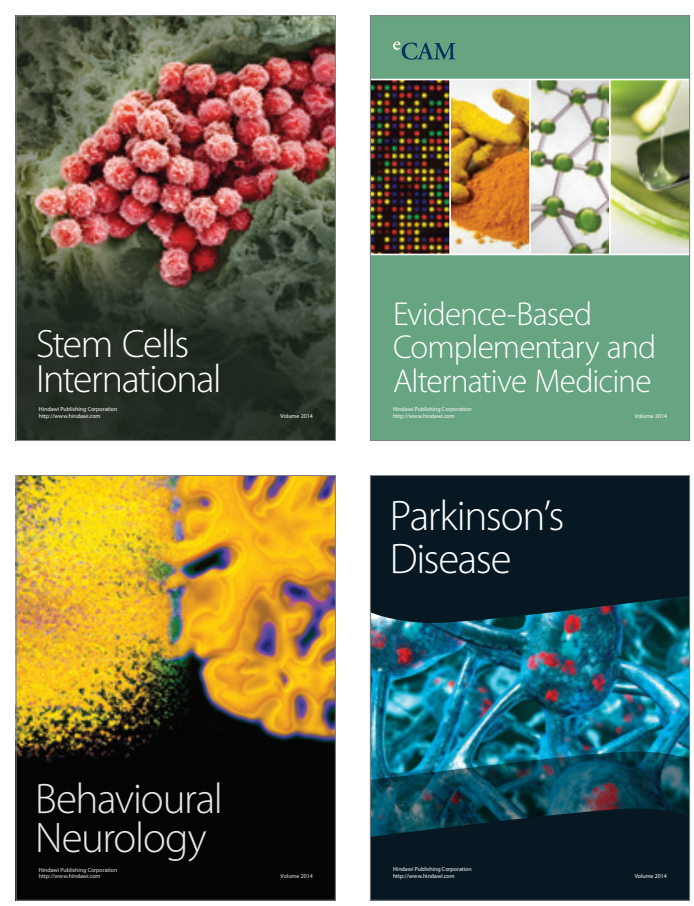

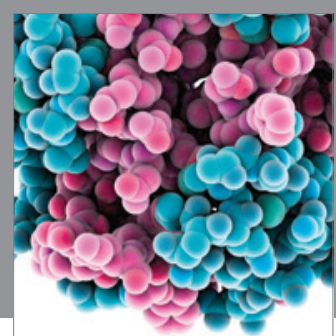

Journal of
Diabetes Research

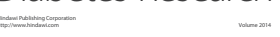

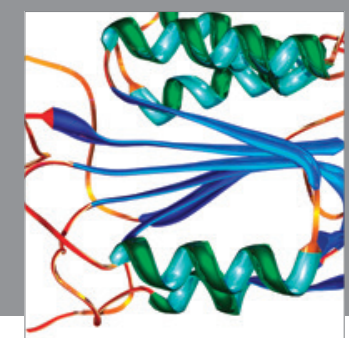

Disease Markers
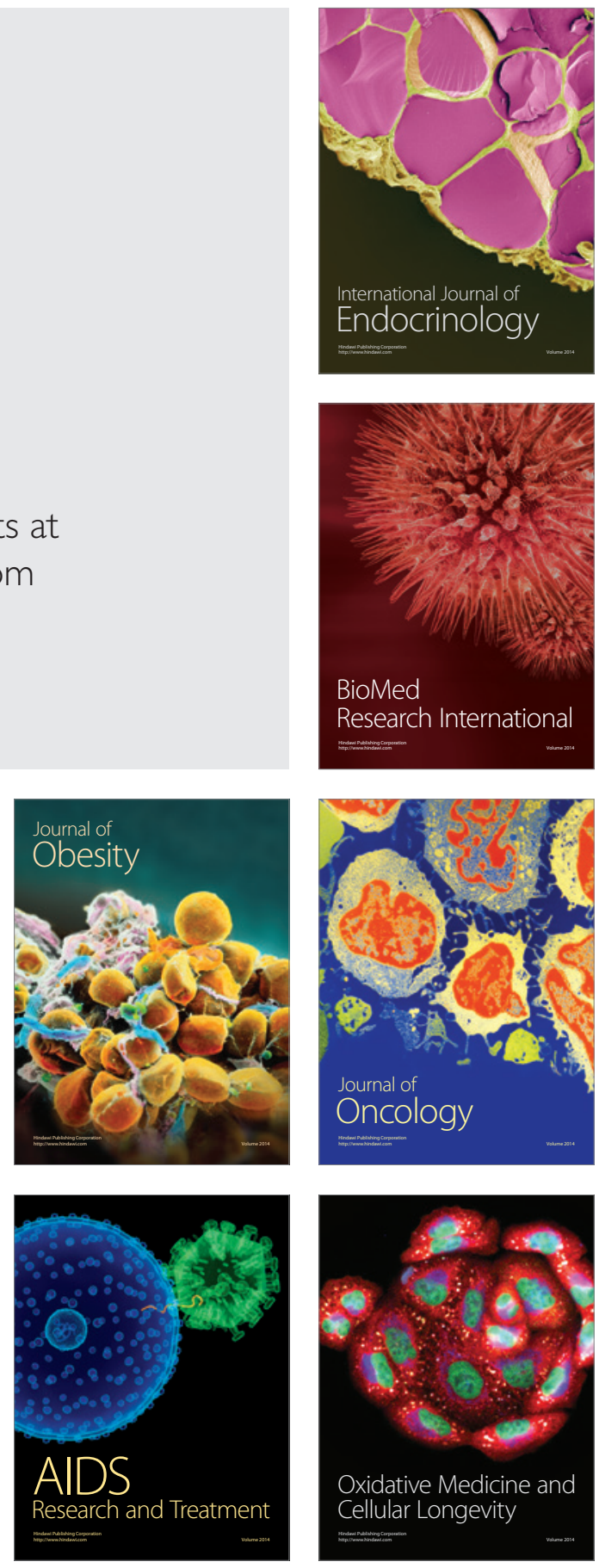